\title{
Reduced ubiquitin C-terminal hydrolase-1 expression levels in dementia with Lewy bodies
}

\author{
Marta Barrachina, ${ }^{\mathrm{a}}$ Esther Castaño, ${ }^{\mathrm{b}}$ Esther Dalfó, ${ }^{\mathrm{a}}$ Tamara Maes, ${ }^{\mathrm{c}}$ \\ Carlos Buesa, ${ }^{\mathrm{d}}$ and Isidro Ferrer ${ }^{\mathrm{a}, \mathrm{e}, *}$ \\ ${ }^{a}$ Institut de Neuropatologia, Servei Anatomia Patològica, IDIBELL-Hospital Universitari de Bellvitge, L'Hospitalet de Llobregat, Spain \\ ${ }^{\mathrm{b}}$ Unitat de Biología, Campus de Bellvitge, Serveis Cientifico-Tècnics, Universitat de Barcelona, Spain \\ 'ORYZON Genomics, Science Park of Barcelona, Spain \\ ${ }^{\mathrm{d}}$ Cell Signaling Group, Department of Biochemistry and Molecular Biology, School of Pharmacy, University of Barcelona, Spain \\ ${ }^{\mathrm{e}}$ Unitat de Neuropatologia Experimental, Departament de Biologia Cel.lular I Anatomia Patologica, Universitat de Barcelona, Hospitalet de Llobregat, Spain
}

Received 4 June 2005; revised 22 October 2005; accepted 13 November 2005

Available online 27 December 2005

Parkinson disease (PD) and dementia with Lewy bodies (DLB) are characterized by the accumulation of abnormal $\alpha$-synuclein and ubiquitin in protein aggregates conforming Lewy bodies and Lewy neurites. Ubiquitin C-terminal hydrolase-1 (UCHL-1) disassembles polyubiquitin chains to increase the availability of free monomeric ubiquitin to the ubiquitin proteasome system (UPS) thus favoring protein degradation. Since mutations in the $U C H L-1$ gene, reducing UPS activity by $50 \%$, have been reported in autosomal dominant PD, and UCHL-1 inhibition results in the formation of $\alpha$-synuclein aggregates in mesencephalic cultured neurons, the present study was initiated to test UCHL-1 mRNA and protein levels in post-mortem frontal cortex (area 8) of PD and DLB cases, compared with agematched controls. TaqMan PCR assays, and Western blots demonstrated down-regulation of UCHL-1 mRNA and UCHL-1 protein in the cerebral cortex in DLB (either in pure forms, not associated with Alzheimer disease: AD, and in common forms, with accompanying AD changes), but not in PD, when compared with age-matched controls. Interestingly, UCHL-1 mRNA and protein expressions were reduced in the medulla oblongata in the same PD cases. Moreover, UCHL-1 protein was decreased in the substantia nigra in cases with Lewy body pathology. UCHL-1 down-regulation was not associated with reduced protein levels of several proteasomal subunits, including 20SX, 20SY, $19 \mathrm{~S}$ and $11 \mathrm{~S} \alpha$. Yet UCHL-3 expression was reduced in the cerebral cortex of PD and DLB patients. Together, these observations show reduced UCHL-1 expression as a contributory factor in the abnormal protein aggregation in DLB, and points UCHL-1 as a putative therapeutic target in the treatment of DLB.

(c) 2005 Elsevier Inc. All rights reserved.

Keywords: Dementia with Lewy Bodies; Parkinson's disease; UCHL; Proteasome; $\alpha$-synuclein

\footnotetext{
* Corresponding author. Institut de Neuropatologia, Servei Anatomia Patològica, IDIBELL-Hospital Universitari de Bellvitge, carrer Feixa Llarga sn, 08907 L'Hospitalet de Llobregat, Spain. Fax: +34 932045301. E-mail addresses: 8082ifa@comb.es, iferrer@csub.scs.es (I. Ferrer). Available online on ScienceDirect (www.sciencedirect.com).
}

Introduction

Parkinson's disease (PD) and Dementia with Lewy bodies (DLB) are considered $\alpha$-synucleinopathies because abnormal $\alpha$ synuclein is aggregated into Lewy bodies and Lewy neurites in selected nuclei of the brain stem, spinal cord, autonomic ganglia. In addition, DLB is characterized by the widespread distribution of LBs and $\alpha$-synuclein-containing neurites in the cerebral cortex (Forno, 1996; Spillantini et al., 1998; Ince et al., 1998; Jellinger and Mizuno, 2003; Ince and McKeith, 2003). DLB is often accompanied by Alzheimer's disease (AD) and this is considered the common form (DLBc); DLB with minimal BA4-amyloid deposits and no tau pathology characterizes the pure form (DLBp) (Kosaka, 1990, 1993). The reasons of abnormal $\alpha$-synuclein accumulation in neurons and neuronal processes in Lewy body diseases are not known but several observations, point to the likelihood that the ubiquitin-proteasome system (UPS) is involved in the pathogenesis of PD and DLB (McNaught and Olanow, 2003; McNaught et al., 2003).

The UPS regulates intracellular protein turnover, and the elimination of misfolded, mutated and damaged proteins (Herschko and Ciechanover, 1998; Glickman and Ciechanover, 2002). The process is initiated with the conjugation of the target protein to a chain of ubiquitin molecules to be recognized by the $26 \mathrm{~S}$ proteasome which is composed of the $20 \mathrm{~S}$ proteasome and the 19S, or PA700, complex. The 20S proteasome contains a 28 subunit catalytic core formed by two outer rings (each with $7 \alpha$ subunits) and two inner rings (X, Y, each with $7 \beta$-subunits), forming a cylindrical structure. The 19S complex recognizes ubiquitinylated proteins tagged for destruction, and unfolds and inserts the proteins into the core of the $20 \mathrm{~S}$ proteasome where they are degraded (Tanaka and Tsurumi, 1997; Ciechanover, 1998; Botchler et al., 1999). In addition to the 19S complex, the 20S proteasome can interact with the $11 \mathrm{~S}$ activator, or PA28 $\alpha \beta$ complex, forming the PA28 proteasome (Groetrup et al., 1996; 
Li and Rechsteiner, 2001). Ubiquitin C-terminal hydrolase L1 (UCHL-1) belongs to a family of enzymes that disassembles polyubiquitin chains to increase the availability of free monomeric ubiquitin to the UPS (Larsen et al., 1996, 1998). Yet UCHL-1 has two opposing enzymatic capacities as ubiquityl ligase activity has been demonstrated in addition to the hydrolase activity (Liu et al., 2002). UCHL-1 is one of the most abundant proteins in the brain, representing $1-2 \%$ of total soluble brain protein (Wilkinson et al., 1989; Solano et al., 2000).

The implications of UCHL-1 in PD are derived from the discovery of the $193 \mathrm{M}$ mutation in the UCHL-1 gene in a German family with autosomal dominant PD (Leroy et al., 1998). This mutation leads to $50 \%$ reduction in the catalytic UPS activity in vitro (Lansbury and Brice, 2002). In contrast, the polymorphism Ser18Tyr in UCHL-1 is associated with a significant lower risk of suffering PD (Maraganore et al., 1999, 2004). Interestingly, Ser18Tyr polymorphism results in selective reduction of ligase activity with preserved hydrolase activity (Liu et al., 2002). Finally, inhibition of UCHL-1 in fetal rat ventral mesencephalic cultures is accompanied by the production of $\alpha$-synuclein aggregates (McNaught et al., 2002a). Recent neuropathological studies have shown classical Lewy pathology and co-aggregation of $\alpha$ synuclein and UCHL-1 in cortical neurons in a deceased sibling of the family affected with the I93M $\alpha$-synuclein mutation who developed, in addition to DOPA-responsive parkinsonism, marked cognitive deficits (Auburger et al., 2005).

These findings prompted the examination of UCHL-1 mRNA by TaqMan PCR assay, and UCHL-1 protein levels by Western blotting, in the frontal cortex of PD, DLBp, DLBc, and agematched controls, obtained with short post-mortem delays. Accompanying determinations of UCHL-1 were carried out in other brain regions as the medulla oblongata and substantia nigra. The present study shows UCHL-1 down-regulation, accompanied by normal expression of several subunits of the 19S, 11S and 20S proteasome, in the frontal cortex in DLB, and points low UCHL-1 expression as a determining factor of the abnormal $\alpha$-synuclein accumulation in DLB.

\section{Material and methods}

\section{Brain samples}

The brains of six patients with PD, seven DLBp, six DLBc, and six aged-matched controls were obtained at autopsy, following informed consent of the patients or their relatives and the approval of the local Ethics Committee. Both genders were represented equally; age range was between 60 and 91 years (mean age 72 years), the average time between death and tissue processing was $8 \mathrm{~h}$. Half of the brain was immediately cut on coronal sections, 1 $\mathrm{cm}$ thick, frozen on dry ice and stored at $-80^{\circ} \mathrm{C}$ until use. In addition, samples $2 \mathrm{~mm}$ thick of the cerebral isocortex, cingulum, hippocampus and entorhinal cortex, and brain stem were fixed with $4 \%$ paraformaldehyde for $24 \mathrm{~h}$, cryoprotected with $30 \%$ saccharose, frozen on dry ice and stored at $-80^{\circ} \mathrm{C}$ until use. For morphological examinations, the brains were fixed by immersion in $10 \%$ buffered formalin for 2 or 3 weeks. The neuropathological study was carried out on de-waxed 4 - $\mu$ m-thick paraffin sections of the frontal (area 8), primary motor, primary sensory, parietal, temporal superior, temporal inferior, anterior cingulated, anterior insular, and primary and associative visual cortices; entorhinal cortex and hippocampus; caudate, putamen and pallidum; medial and posterior thalamus; subthalamus; Meynert nucleus; amygdala; midbrain (two levels), pons and medulla oblongata; and cerebellar cortex and dentate nucleus. The sections were stained with hematoxylin and eosin, luxol fast blue-Klüver Barrera, and for immunohistochemistry to glial fibrillary acidic protein, CD68 and Licopericum esculentum lectin for microglia, $3 \mathrm{~A} 4$ amyloid, pantau, phosphorylation-specific tau Thr181, Ser202, Ser214, Ser262, Ser396 and Ser422, and $\alpha B$-crystallin, $\alpha$-synuclein and ubiquitin.

Neuropathological characterization of PD was accordingly to well-established neuropathological criteria (Jellinger and Mizuno, 2003). Neuropathological characterization of DLB was according to consensus guidelines of the consortium on DLB international workshop (McKeith et al., 1996, 2000). Associated AD stages were further established depending on the amyloid deposition burden and neurofibrillary pathology following the nomenclature of Braak and Braak (1999). Stages of amyloid deposition refer to initial deposits in the basal neocortex (stage A), deposits extended to the association areas of the neocortex (stage B), and heavy deposition throughout the entire cortex (stage C). Stages of neurofibrillary pathology correspond to transentorhinal (I-II), limbic (III-IV) and neocortical (V and VI). To further refine $\alpha$ synuclein pathology, staging of brain pathology related to sporadic PD proposed by Braak et al. was used in the present study. Basically, stages 1 and 2 affect the medulla oblongata plus the pontine tegmentum; stage 3 , the midbrain; stage 4 , the basal prosencephalon and mesocortex; and stages 5 and 6 , the neocortex (Braak et al., 2003). Clinically, all cases of PD had suffered from classical PD lasting from 8 to 15 years, and none of them had cognitive impairment. Cases with DLB fulfilled the clinical criteria proposed by the consortium on DLB international workshop (McKeith et al., 1996, 2000). Control cases were considered in the absence of neurological symptoms and signs, and no abnormalities in the neuropathological study. The main neuropathological data in the present series are summarized in Table 1. Further details in DLB cases can be found elsewhere (Dalfó et al., 2004).

Biochemical studies were carried out in frozen samples of the frontal cortex (area 8) in DLB, in the cerebral cortex and medulla oblongata in PD, and in the substantia nigra in DLB and PD. Control and diseased brains were processed in parallel.

In addition, samples of the frontal cortex from one control individual were obtained at $3 \mathrm{~h}$ post-mortem and immediately frozen (time 0 ), or stored at $4^{\circ} \mathrm{C}$ for $3 \mathrm{~h}, 6 \mathrm{~h}, 22 \mathrm{~h}$ and $48 \mathrm{~h}$, and then frozen to mimic variable post-mortem delay in tissue processing.

\section{$m R N A$ isolation}

mRNA isolation was carried out in two steps. Total RNA was isolated using TRizol Reagent (Life Technologies) followed by the RNeasy Protect Mini Kit (Qiagen). Frozen human brain tissues were directly homogenized in $1 \mathrm{ml}$ of TRizol reagent per $100 \mathrm{mg}$ tissue, and total RNA was extracted following the protocol suggested by the supplier. Purified total RNA was re-suspended in $100 \mu \mathrm{l}$ of RNase-free water, and mRNA purification was obtained following the protocol provided with the RNeasy Protect Mini Kit with minor modifications; DNase I treatment was discarded due to the elimination of genomic DNA during TRizol extraction. The concentration of each sample was obtained from $\mathrm{A}_{260}$ measurements. For transcriptomic purposes, RNA samples 
Table 1

Summary of the main clinical and neuropathological findings in the present series

\begin{tabular}{|c|c|c|c|c|c|c|c|}
\hline \multirow[t]{2}{*}{ Case } & \multirow[t]{2}{*}{ Disease } & \multirow[t]{2}{*}{ Gender } & \multirow[t]{2}{*}{ Age (year) } & \multirow[t]{2}{*}{ Post-mortem (h) } & \multicolumn{2}{|c|}{ Braak stages AD } & \multirow[t]{2}{*}{ Braak stages PD } \\
\hline & & & & & BA4 amyloid & NFT & \\
\hline$\overline{1}$ & Control & $\mathrm{M}$ & 63 & 17 & 0 & 0 & 0 \\
\hline 2 & Control & M & 70 & 13 & 0 & 0 & 0 \\
\hline 3 & Control & M & 79 & 7 & 0 & II & 0 \\
\hline 4 & Control & $\mathrm{F}$ & 65 & 4 & 0 & I & 0 \\
\hline 5 & Control & $\mathrm{F}$ & 80 & 11 & 0 & $\mathrm{I}$ & 0 \\
\hline 6 & Control & $\mathrm{F}$ & 82 & 11 & A & III & 0 \\
\hline 7 & PD & M & 66 & 5 & 0 & I & 3 \\
\hline 8 & $\mathrm{PD}$ & $\mathrm{M}$ & 81 & 5 & A & II & 4 \\
\hline 9 & $\mathrm{PD}$ & M & 88 & 2 & 0 & II & 4 \\
\hline 10 & $\mathrm{PD}$ & M & 70 & 9 & 0 & 0 & 4 \\
\hline 11 & $\mathrm{PD}$ & $\mathrm{F}$ & 60 & 4 & A & 0 & 4 \\
\hline 12 & $\mathrm{PD}$ & $\mathrm{F}$ & 70 & 4 & 0 & 0 & 4 \\
\hline 13 & DLBp & M & 60 & 8 & A & $\mathrm{I}$ & 6 \\
\hline 14 & DLBp & M & 68 & 12 & B & 0 & 6 \\
\hline 15 & DLBp & M & 71 & 6 & B & 0 & 5 \\
\hline 16 & DLBp & M & 81 & 16 & A & I & 6 \\
\hline 17 & DLBp & M & 85 & 7 & B & II & 6 \\
\hline 18 & DLBp & $\mathrm{F}$ & 70 & 8 & 0 & 0 & 5 \\
\hline 19 & DLBp & $\mathrm{F}$ & 77 & 5 & B & 0 & 5 \\
\hline 20 & DLBc & $\mathrm{M}$ & 78 & 6 & $\mathrm{C}$ & $\mathrm{V}$ & 6 \\
\hline 21 & DLBc & M & 78 & 7 & $\mathrm{C}$ & V & 6 \\
\hline 22 & DLBc & $\mathrm{F}$ & 71 & 5 & $\mathrm{C}$ & $\mathrm{V}$ & 5 \\
\hline 23 & $\mathrm{DLBc}$ & $\mathrm{F}$ & 78 & 7 & $\mathrm{C}$ & VI & 6 \\
\hline 24 & DLBc & $\mathrm{F}$ & 78 & 13 & $\mathrm{C}$ & IV & 5 \\
\hline 25 & DLBc & $\mathrm{F}$ & 91 & 5 & $\mathrm{C}$ & $\mathrm{V}$ & 6 \\
\hline
\end{tabular}

Parkinson's disease (PD), Diffuse Lewy body disease: Dementia with Lewy bodies, pure form (DLBp) and common form (DLBc), and controls. M: male, F: female. NFT: neurofibrillary tangle. Braak stages refers to Braak and Braak Alzheimer's disease (AD) changes (Braak and Braak, 1999). Staging of $\alpha-$ synuclein pathology (Lewy bodies and Lewy neurites) related to sporadic Parkinson's disease (PD) was according to Braak et al. (2003).

were additionally analyzed using the Agilent 2100 BioAnalyzer. The Bioanalyzer calculates fragment size and sample concentration, and the ratio of the surface below the $18 \mathrm{~S}$ and $28 \mathrm{~S}$ peaks was used for determination of RNA quality.

\section{cDNA synthesis and TaqMan PCR}

For each $10 \mu \mathrm{l}$ reverse transcription reaction, $200 \mathrm{ng}$ human RNA (in $3.85 \mu \mathrm{l}$ water) was mixed with $2.5 \mu \mathrm{M}$ oligodT primer, $1 \times$ TaqMan RT buffer, $5.5 \mathrm{mM} \mathrm{MgCl}_{2}, 500 \mu \mathrm{M}$ each of dATP, dTTP, dCTP and dGTP, $0.08 \mathrm{U}$ RNase inhibitor and $0.31 \mathrm{U}$ MultiScribe Reverse Transcriptase (Applied Biosystems). Reactions were carried out at $25^{\circ} \mathrm{C}$ for $10 \mathrm{~min}$ to maximize primer-RNA template binding, followed by $30 \mathrm{~min}$ at $48^{\circ} \mathrm{C}$, and then by incubation for $5 \mathrm{~min}$ at $95^{\circ} \mathrm{C}$ to deactivate reverse transcriptase. Parallel reactions for each RNA sample were run in the absence of MultiScribe Reverse transcriptase to assess the degree of contaminating genomic DNA.

The TaqMan probe (Applied Biosystems) anneals to one strand of the DNA template between forward and reverse PCR primers. It contains a reporter dye which is released by Taq polymerase during the amplification step, with the fluorescence originated being proportional to the amount of product accumulated.

Primers and fluorescence probes specific for human UCHL-1 and $\beta$-actin were purchased from TaqMan $\subset$ Gene Expression Assays (Applied Biosystems). Human $\beta$-actin was used as endogenous references.

TaqMan PCR assays for UCHL- 1 and endogenous reference $\beta$ actin were performed in triplicate on cDNA samples in 96-well optical plates on an ABI Prism 7700 Sequence Detection system (PE Applied Biosystems). The plate was capped using optical caps (Applied Biosystems). For each $20 \mu 1$ TaqMan reaction, $9 \mu 1$ cDNA (diluted 1/50, which corresponds approximately to cDNA from 4 ng of RNA) was mixed with $1 \mu 120 \times$ TaqMan $($ Gene Expression Assay Mix and $10 \mu \mathrm{l}$ of $2 \times$ TaqMan Universal PCR Master Mix (Applied Biosystems). Parallel assays for each sample were carried out using primers and probes with $\beta$-actin for normalization. The reaction was carried out using the following parameters: $50^{\circ} \mathrm{C}$ for 2 $\min , 95^{\circ} \mathrm{C}$ for $10 \mathrm{~min}$, and 40 cycles of $95^{\circ} \mathrm{C}$ for $15 \mathrm{~s}, 60^{\circ} \mathrm{C}$ for 1 min. Standard curves were prepared for UCHL-1 and for the endogenous reference $\beta$-actin using serial dilutions of control human brain RNA. Finally, all TaqMan PCR data were captured using the Sequence Detector Software (SDS version 1.9; Applied Biosystems).

\section{Gel electrophoresis and Western blotting}

Frozen frontal cortex, substantia nigra and medulla oblongata $(100 \mathrm{mg})$ was directly homogenized in $1 \mathrm{ml}$ lysis buffer $(20 \mathrm{mM}$ HEPES, $10 \mathrm{mM} \mathrm{KCl}, 1.5 \mathrm{mM} \mathrm{MgCl} 2,1 \mathrm{mM}$ EDTA, $1 \mathrm{mM}$ EGTA, $1 \mathrm{mM}$ DDT, $2 \mathrm{mM}$ PMSF, $1 \mu \mathrm{g} / \mathrm{ml}$ aprotinin, leupeptin and pepstatin) and then sonicated. Lysates were centrifuged at 5000 rpm for $10 \mathrm{~min}$ at $4^{\circ} \mathrm{C}$ and protein concentration was determined with BCA (Pierce) method. $50 \mu \mathrm{g}$ of total protein were boiled at $95^{\circ} \mathrm{C}$ for 3 min and loaded in SDS-polyacrylamide gels with Trisglycine running buffer. Proteins were electrophoresed using a miniprotean system (Bio-Rad) and transferred to nitrocellulose membranes (Bio-Rad) with a Trans-Blot SD Semi-Dry Transfer Cell 
(Bio-Rad) for $45 \mathrm{~min}$ at $40 \mathrm{~mA}$. Nitrocellulose membranes were blocked with Tween 20 TBS (TBST) containing 5\% skimmed milk for $30 \mathrm{~min}$. Subsequently, the membranes were incubated at $4^{\circ} \mathrm{C}$ overnight with one of the primary antibodies in TBST containing $3 \%$ BSA. The following antibodies were used: anti-UCHL-1 (AB5937, Chemicon), anti-UCHL-3 (RB4187, Abgent), anti- $\beta$ actin (clone AC-74, Sigma), anti-proteasome 19S $\beta$ (PA1-973, Affinity BioReagents), anti-proteasome activator 11S $\alpha$ (PA1-960, Affinity BioReagents), anti-proteasome 20SX (PA1-977, Affinity BioReagents) and anti-proteasome 20SY (PA1-978, Affinity BioReagents). All the antibodies were used at a dilution of 1:500 except for UCHL-3 (1:200) and $\beta$-actin (1:5,000). After primary antibody incubation, the membranes were washed three times with TBST for $5 \mathrm{~min}$ at room temperature, and then incubated with antirabbit or anti-goat $\operatorname{IgG}$ antibody labeled with horseradish peroxidase (Dako) at a dilution of 1:1,000 (1:5,000 for $\beta$-actin) for $1 \mathrm{~h}$ at room temperature. Subsequently, the membranes were washed four times, 5 min each, with TBST at room temperature, and developed with the chemiluminescence ECL Western blotting system (Amersham/Pharmacia) followed by apposition of the membranes to autoradiographic films (Hyperfilm ECL, Amersham).

\section{Data analysis}

The densitometric quantification of Western Blot bands was done with the TotalLab v2.01 software. Statgraphics Plus v5 software was used for statistical analysis.

\section{Immunohistochemistry}

De-waxed sections 5- $\mu$ m-thick of the frontal cortex and medulla oblongata were processed for immunohistochemistry following the streptavidin LSAB method (Dako). Sections were boiled in citrate buffer to enhance antigenicity. After incubation with methanol and $\mathrm{H}_{2} \mathrm{O}_{2}$ in PBS and normal serum, the sections were incubated with rabbit polyclonal anti-UCHL-1 antibody (Abcam) at a dilution of $1: 200$. Following incubation with the primary antibody, the sections were incubated with LASB for $15 \mathrm{~min}$ at room temperature. The peroxidase reaction was visualized with diaminobenzidine and $\mathrm{H}_{2} \mathrm{O}_{2}$. Control of the immunostaining included omission of the primary antibody; no signal was obtained following incubation with only the secondary antibody. Sections were slightly counterstained with hematoxylin. Cortical sections from two cases of corticobasal degeneration with large ballooned neurons in the cerebral cortex were used as a positive control.

\section{Results}

\section{UCHL-1 $m R N A$}

TaqMan PCR assays were carried out in control and diseased brains. The ABI Prism 7700 measures the fluorescent accumulation of PCR product by continuous monitoring cycle threshold $(C \mathrm{t})$, which is an arbitrary value assigned manually to a level somewhere above baseline, in the exponential phase of PCR where there are no rate-limiting components. The $C \mathrm{t}$ value sets the point at which the sample amplification plot crosses the threshold (Fig. 1A). The analysis of a good reference mRNA is indispensable to correctly determine mRNA levels. Prior to determining the UCHL1 levels, a set of primer combinations of Taqman probes was tested
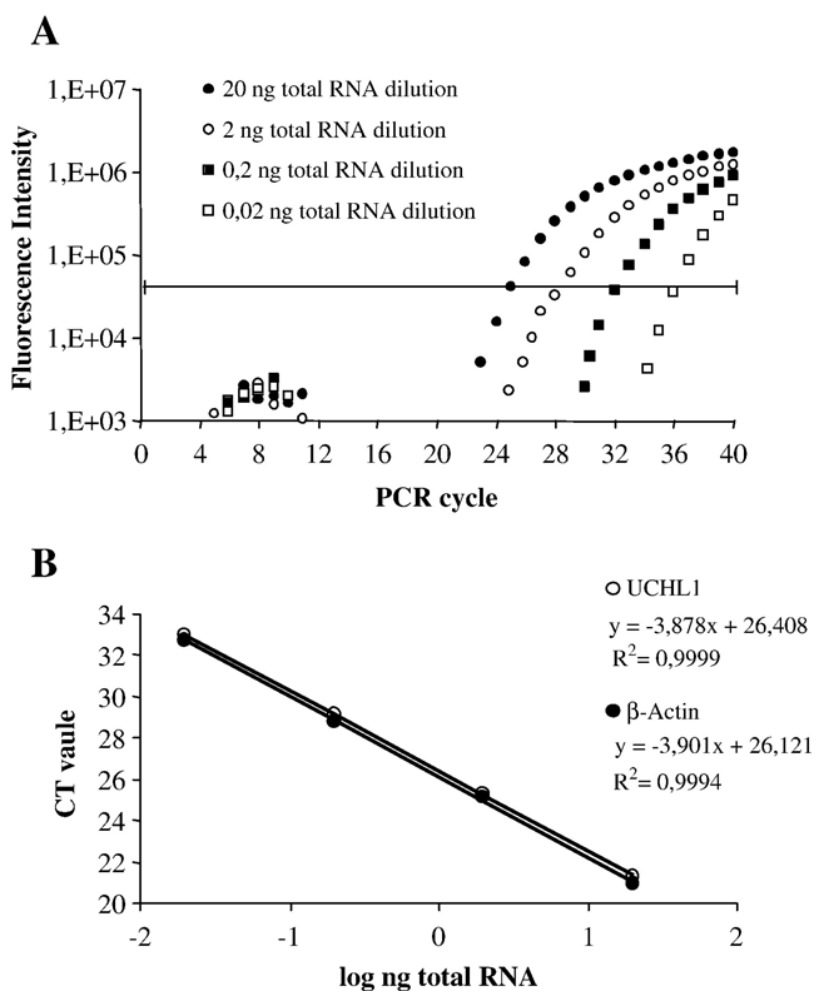

Fig. 1. (A) Amplification plot of UCHL-1 using serial dilutions of control human brain RNA. The horizontal line represents the threshold line adjusted manually in the exponential phase. The fluorescence intensity augments with PCR cycles. The number of PCR cycles at which the fluorescence intensity exceeds the threshold line is defined as the $C \mathrm{t}$ value on which the relative quantification is based. (B) Representative standard curves for $\beta$-actin and UCHL-1 constructed from several concentrations of control human brain RNA. Ct values ( $y$ axis) vs. log of several RNA concentrations of control samples ( $x$ axis) show a reverse linear correlation.

to identify an appropriate control mRNA that displayed minimal variation between different brain samples. An often used control (GAPDH) was excluded as both we and others have found that this mRNA is subject to post-mortem degradation in mRNA samples (Auer et al., 2003). The $\beta$-actin $\Delta C \mathrm{t}$ value $\left(C \mathrm{t}_{\text {control }}-C \mathrm{t}_{\text {pathology }}\right)$, calculated for PD, DLBp and DLBc showed no significant differences among pathologies (Fig. 2A) and, therefore, $\beta$-actin was chosen as a reference.

For each experimental sample, the amount of target and endogenous reference was determined from the appropriate standard curve which was plotted showing the cycle threshold, $C t$ (year), versus the log of ng total control RNA (Fig. 1B). Then the amount of each target UCHL-1 was divided by the endogenous reference $\beta$-actin amount to obtain a normalized target value which permits determination of the relative mRNA levels of UCHL-1 in control and in diseased samples.

Decreased UCHL-1 relative mRNA levels were observed in the cerebral cortex in DLBp and in DLBc when compared with controls: $P<0.01$ for DLBp and $P<0.05$ for DLBc, ANOVA with post hoc Fisher's least significant difference (LSD) test (Fig. 2B). Relative UCHL-1 mRNA levels in the cerebral cortex were not modified in PD when compared with control values. Reduced UCHL-1 relative mRNA levels were however observed in the medulla oblongata in the same PD cases: $P<0.01$ (data not shown). 


\section{UCHL-1 protein}

UCHL-1 protein levels in the frontal cortex were reduced in DLBp and DLBc, but not in PD when compared with controls $(P<$ 0.01 for DLBp and $P<0.05$ for DLBc, ANOVA with post hoc LSD test) (Fig. 2C).

Interestingly, UCHL-1 protein levels were reduced in the medulla oblongata in $\mathrm{PD}$, when compared with controls $(P<0.05$, ANOVA with post hoc LSD test) (Fig. 3A). Similarly, UCHL-1 protein levels were decreased in diseases with Lewy bodies (Fig. 3B).

Protein decrease was not the result of post-mortem degradation, as UCHL-1 protein levels were only modified after $22 \mathrm{~h}$ in a paradigm to analyze protein degradation by cumulative delay in the tissue processing (data not shown).

A
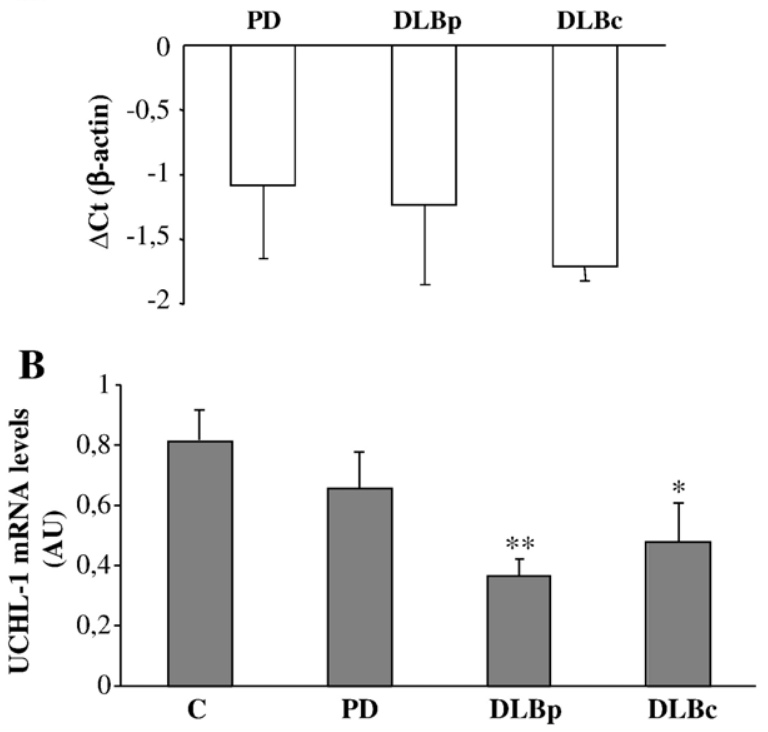

C
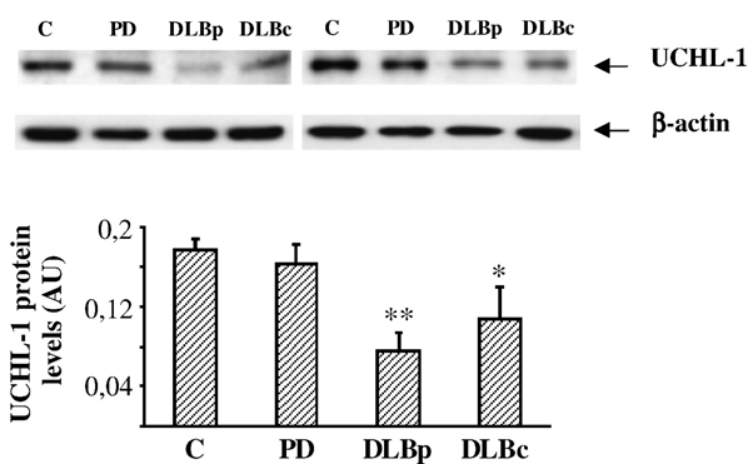

Fig. 2. Relative $U C H L-1$ gene expression in the frontal cortex of controls $(\mathrm{C}, n=6)$, Parkinson's disease (PD, $n=6)$, Dementia with Lewy bodies, pure form (DLBp, $n=7$ ) and common form (DLBc, $n=6$ ). (A) $\Delta C$ t values (mean \pm SEM) were calculated for $\beta$-actin in PD, DLBp and DLBc. (B) UCHL-1 mRNA levels (mean \pm SEM) normalized with $\beta$-actin. (C) UCHL1 protein levels $(25 \mathrm{kDa})$, as detected by Western Blot in total frontal cortex (area 8 ) homogenates. $\beta$-actin $(45 \mathrm{kDa})$ is blotted to control protein loading. The image is representative of all the samples indicated in the Table 1, whereas the densitometric analysis of UCHL-1 protein levels (mean \pm SEM) with TotalLab v2.01 software is the result of all the samples included in the series. UCHL-1 protein values were normalized with $\beta$-actin. AU: arbitrary units. $* P<0.05$ and $* * P<0.01$ compared to control samples (ANOVA with post hoc LSD test).
A
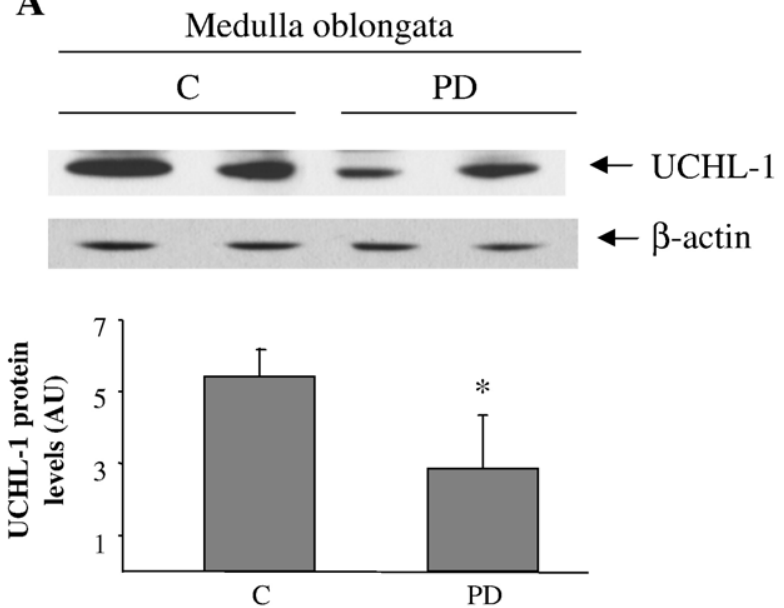

B
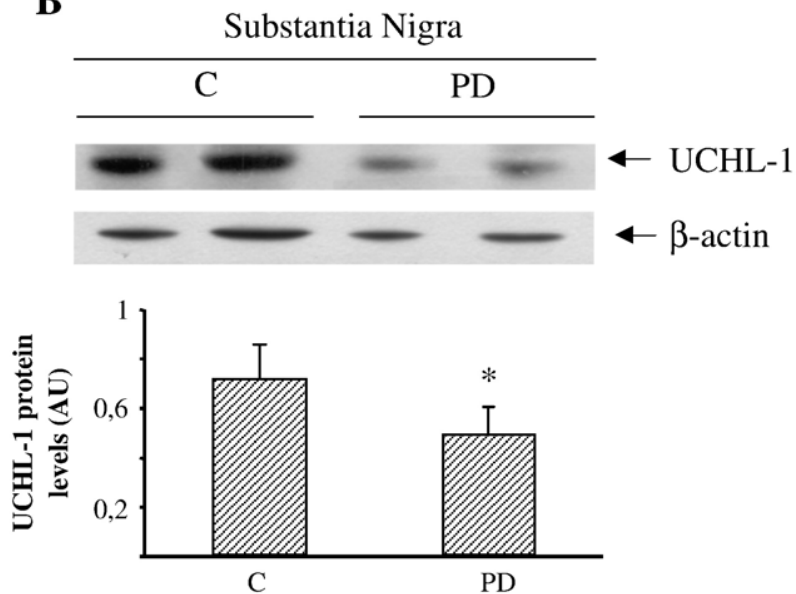

Fig. 3. (A) UCHL-1 protein levels are detected in Western blots of total homogenates of the medulla oblongata of control (C) and Parkinson's disease (PD). $\beta$-actin $(45 \mathrm{kDa})$ is blotted to control protein loading. The figure is representative of four control and PD cases. The graphic shows the densitometric analysis of UCHL-1 protein levels (mean \pm SEM) with TotalLab v2.01 software. UCHL-1 protein values are normalized with $\beta$ actin. ${ }^{*} P<0.05$ compared to control samples (ANOVA with post hoc LSD test). (B) UCHL-1 protein levels are detected in Western blots of total homogenates of the substantia nigra of control $(\mathrm{C})$ and Parkinson's disease (PD). $\beta$-actin $(45 \mathrm{kDa})$ is blotted to control protein loading. The figure is representative of four control and Lewy body disease cases. $* P<$ 0.05 compared to control samples (ANOVA with post hoc LSD test).

\section{Proteasomal proteins}

UCHL-1 down-regulation in DLB was not accompanied by a decrease in the constitutive levels of the 20SX and 20SY $\beta$ subunits of the $26 \mathrm{~S}$ proteasome, subunit S19 $\beta$ of the 19S complex and subunit $\alpha$ of the $11 \mathrm{~S}$ (PA28 $\alpha$ ) activator (Fig. 4).

\section{UCHL-3 protein}

UCHL-3 protein levels in the cerebral cortex were reduced in PD, DLBp and DLBc when compared with controls $(P<0.001$ for $\mathrm{PD}$, and $P<0.05$ for DLBp and DLBc, ANOVA with post hoc LSD test) (Fig. 5). 


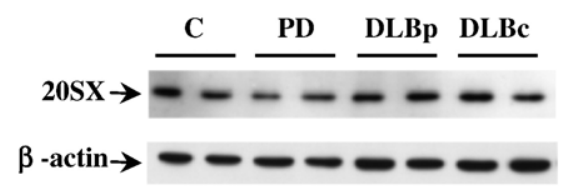

20SX
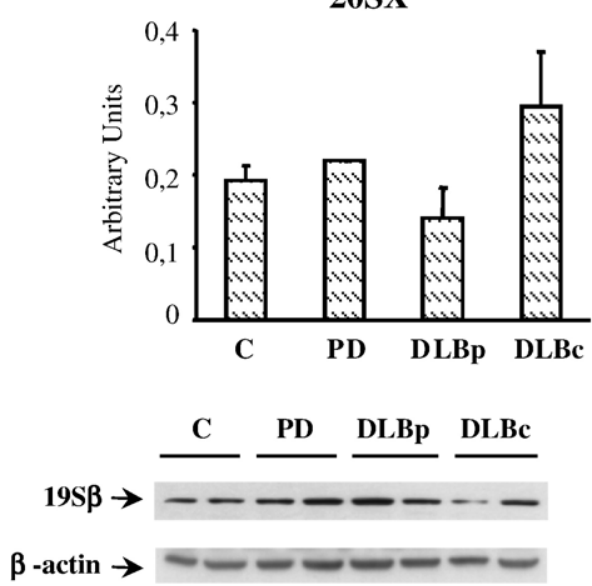

19S

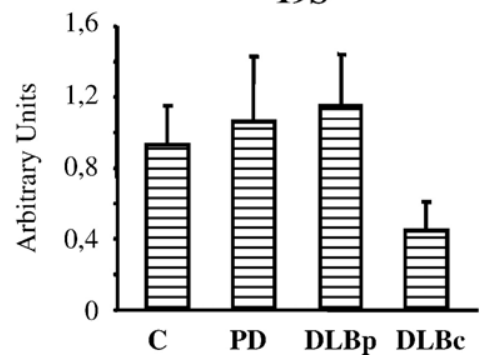

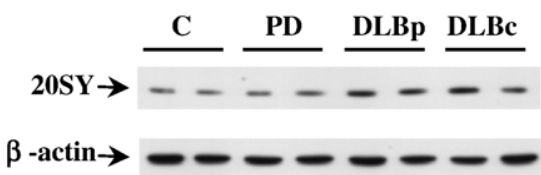

20SY
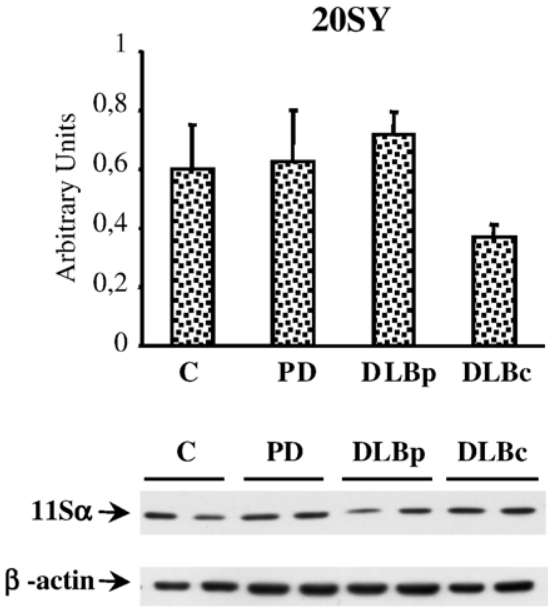

$11 \mathrm{~S} \alpha$

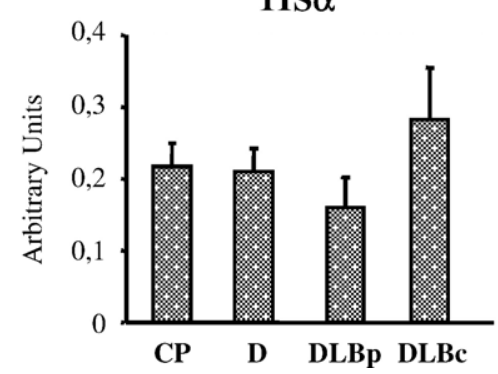

Fig. 4. Protein levels of proteasome subunits in the frontal cortex of controls $(\mathrm{C}, n=6)$, Parkinson's disease (PD, $n=6)$, Dementia with Lewy bodies, pure form (DLBp, $n=7$ ) and common form (DLBc, $n=6$ ): $\beta$-subunits of the 20S complex, 20SX and 20SY, 19S complex and 11S $\alpha$ activator. $\beta$-actin is blotted to control protein loading. The image is representative of all the samples indicated in the Table 1 . Densitometric analysis of proteasome subunit levels (mean \pm SEM) with TotalLab v2.01 software. UCHL-1 protein values were normalized with $\beta$-actin. No differences are seen between control, and diseased cases.

Immunohistochemistry

UCHL-1 decorated the cytoplasm of neurons in the cerebral cortex and medulla oblongata in control and diseased brains. No clear reduction of UCHL-1 immunostaining was seen in DLB cases when compared with controls (data not shown). No differences were seen in small and large cortical neurons between control and DLB cases. UCHL-1 was observed equally in neurons
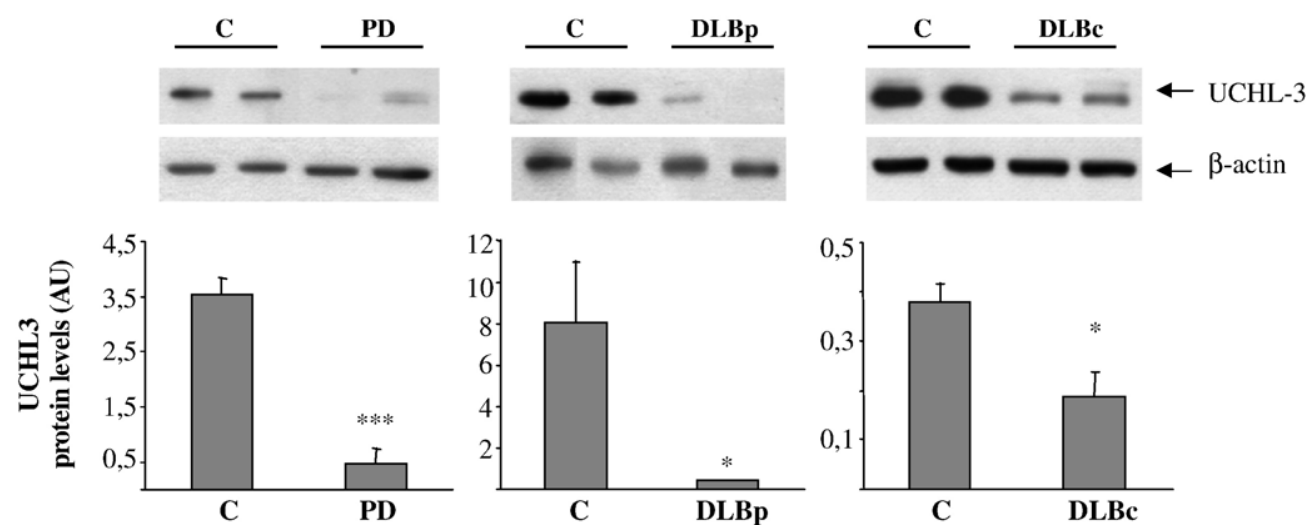

Fig. 5. UCHL-3 protein levels (26 kDa) are detected in Western blots of total frontal cortex homogenates in control cases $(\mathrm{C}, n=6)$, Parkinson's disease (PD, $n=6$ ), Dementia with Lewy bodies, pure form (DLBp, $n=7$ ) and DLB common form (DLBc, $n=6$ ). $\beta$-actin ( $45 \mathrm{kDa})$ is blotted to control protein loading. The image is representative of all the samples indicated in Table 1 . The graphic shows the densitometric analysis of UCHL-3 protein levels (mean \pm SEM) after normalization with $\beta$-actin. ${ }^{*} P<0.05,{ }^{* * *} P<0.001$ compared to control samples (ANOVA with post hoc LSD test). 
with Lewy bodies and in neurons with Lewy bodies in the substantia nigra in the substantia nigra and selected nuclei of the medulla oblongata (data not shown). Lewy bodies and Lewy neurites were not recognized with the anti-UCHL-1 antibodies here used, although strong UCHL-1 immunostaining was found in the cytoplasm of ballooned neurons in two cases of corticobasal degeneration used as positive controls.

\section{Discussion}

Abnormal activity of the UPS has been postulated as a crucial factor in the irregular degradation of $\alpha$-synuclein leading to the formation of Lewy bodies and Lewy neurites in PD and related $\alpha$ synucleinopathies (McNaught and Olanow, 2003, McNaught et al., 2003). This is mainly based on the observation of impaired 26S activity and reduced expression of $20 \mathrm{~S} \alpha$-subunits in the substantia nigra in PD (McNaught and Jenner, 2001; McNaught et al., 2001, 2002 b), whereas no changes in $26 \mathrm{~S}$ activity occur in the cerebral cortex of PD (McNaught and Olanow, 2003). However, this may be not the unique mechanism related with the UPS to explain abnormal $\alpha$-synuclein degradation. Preserved proteasomal activity has been noted in the cerebral cortex in DLB and ubiquitination of $\alpha$-synuclein is not necessarily associated with impairment of proteasome function (Tofaris et al., 2003).

UCHL-1 associates with ubiquitin in neuronal cells and maintains free ubiquitin levels in neurons. Loss of UCHL-1 reduces free ubiquitin, and leads to inadequate ubiquitylation and protein accumulation in neurons (Osaka et al., 2003). As an example, inhibition of UCHL-1 in rat ventral mesencephalic neurons induces intracellular $\alpha$-synuclein aggregates (McNaught et al., 2002a). Moreover, UCHL-1 mutation (I93M) reported in autosomal dominant PD reduces catalytic UPS activity in vitro (Nishikawa et al., 2003), and is associated with parkinsonism, cognitive deficits and cortical Lewy pathology (Auburger et al., 2005). Deletion of exons 7 and 8 of $U C H L-1$ in mice suffering from gracile axonal dystrophy is characterized by accumulation of ubiquitin-positive protein deposits in affected sensory and motor neurons (Saigoh et al., 1999). Yet UCHL-1 transgenic mice do not develop a parkinsonian phenotype (Mukoyama et al., 1989; Miura et al., 1993; Oda et al., 1992; Saigoh et al., 1999; Kurihara et al., 2001). Together, these observations show abnormal protein degradation and neuronal degeneration as a result of irregular UCHL-1 protein targeting, although resulting divergent phenotypes probably depend on a combination of several conditioning factors.

The present study has shown reduced UCHL-1 mRNA and UCHL-1 protein expression in the frontal cortex in DLBp and DLBc, but not in the frontal cortex in PD. Yet UCHL-1 mRNA and protein expressions are reduced in the medulla oblongata in the same PD cases, and UCHL-1 protein levels are reduced in the substantia nigra in cases with Lewy pathology. Interestingly, reduction of UCHL-1 mRNA has been recently described in the striatum and substantia nigra in PD (Miller et al., in press). Such decrease is not related with degradation of mRNA or protein resulting from postmortem delay, as UCHL-1 protein levels are maintained up to 22 $\mathrm{h}$ after death in a paradigm of delayed tissue processing mimicking post-mortem autolytic degradation. These changes are not related with the presence of AD-related changes, as similar results were observed in DLB cases with and without neurofibrillary tangles, and with or without amyloid plaques in the frontal cortex. Finally, these changes are probably not the result of cell death as other proteins including those related with the proteasomal pathway have no modifications in their expression levels. In contrast, UCHL-1 reduction correlates with the presence of morphologic $\alpha$-synuclein aggregates in diseases with Lewy bodies.

UCHL-3, another ubiquitin C-terminal hydrolase ubiquitously distributed (Kurihara et al., 2000) was also examined for comparative purposes. Reduced UCHL-3 protein levels have been found in the frontal cortex in PD as well as in DLB patients. Therefore, in contrast to UCHL-1, there is no association between the presence of cortical Lewy bodies and low UCHL-3 expression levels. In this line, in vitro studies using a crude cell-free system where $\alpha$-synuclein was conjugated to histidine-tagged ubiquitin revealed that the addition of UCHL-3 had little effect, whereas the addition of UCHL-1 rapidly consumed the $\alpha$-synuclein-ubiquitin conjugates and produced a trace amount of free $\alpha$-synuclein (Liu et al., 2002). These results are in accordance with our findings and point out the role of reduced UCHL-1 in the formation of protofibril-to-fibril/Lewy body transformation.

Interestingly, UCHL-1CHL-3 double-knockout mice display a more severe axonal and cell body degeneration of the gracile tract than the observed in simple UCHL-1 transgenic mice (Kurihara et al., 2001). Since simple UCHL-3 knockout mice do not develop neurological disease, it has been concluded that UCHL-1 and UCHL-3 have separate and overlapping functions in the maintenance of neurons within the gracile tract (Kurihara et al., 2001). It is not known the implication of reduced UCHL-3 expression in addition to the reduced expression of UCHL-1 in the frontal cortex in DLB cases.

Reduction of UCHL-1 protein levels in DLB is not accompanied by a decrease in the expression of other components of the UPS, including subunits 20SX and 20SY, 19S complex and 11S $\alpha$ subunit of the PA28 activator, thus indicating selective downregulation of UCHL-1 in the DLB cerebral cortex.

Interestingly, UCHL-1 is markedly modified by oxidation in PD and AD (Choi et al., 2004). As a consequence, irregular UCHL-1 in certain neurodegenerative diseases is the result of multiple mechanisms, including down-regulation of mRNA induction and protein expression, and oxidative damage. UCHL-1 may be sequestered or not by abnormal protein aggregates. Seminal studies have shown UCHL immunoreactivity in ubiquitinated inclusions characteristics of human neurodegenerative diseases, including Lewy bodies (Lowe et al., 1990). However, other studies have shown no UCHL-1 immunostaining in PD although UCHL-1 immunoreactivity was present in neurons with neurofibrillary tangles in AD (Choi et al., 2004). The present immunohistochemical studies are in agreement with the later observations showing no UCHL-1 immunoreactivity in Lewy bodies and Lewy neurites, but strong UCHL-1 immunoreactivity in the cytoplasm of ballooned neurons in corticobasal degeneration used here as a positive control.

In summary, the present study has shown down-regulation of UCHL-1 in the frontal cortex of cases suffering from DLB, and in the substantia nigra and medulla oblongata in PD and DLB. Since UCHL-1 participates in the degradation of proteins via UPS, abnormal UCHL-1 levels may interfere with normal protein processing and may contribute to Lewy body formation in DLB and other Lewy body diseases. Whether additional reduction in UCHL-3 expression may act as a contributory factor remains to be elucidated. The present findings point UCHL-1 as a putative therapeutic target in the treatment of DLB. 


\section{Acknowledgments}

This work was supported in part by FIS grants P102/0004, G03/ 167 and C03/06, and European Project Brain Net II to I.F., and by FIS grant01/0818 to C.B. We wish to thank T. Yohannan for editorial assistance.

\section{References}

Auburger, G., Kessler, K., Kang, J.S., Gispert, S., Stoltenburg, G., Braak, H., 2005. Is the PARK5 I93M mutation a cause of Parkinson's disease with cognitive deficits and cortical Lewy Pathology? Abstracts 16th International Congress on Parkinson's Disease and Related Disorders, Berlin, June, 2005. Parkinsonism Rel. Disord. 11 (Suppl. 2), 252.

Auer, H., Lyianarachchi, S., Newsom, D., Klisovic, M.I., Marcucci, G., Kornacker, K., 2003. Chipping away at the chip bias: RNA degradation in microarray analysis. Nat. Genet. 35, 292-293.

Botchler, M., Ditzel, L., Groll, M., Hartmann, C., Huber, R., 1999. The proteasome. Annu. Rev. Biophys. Biomol. Struct. 28, 295-317.

Braak, H., Braak, E., 1999. Temporal sequence of Alzheimer's disease related pathology. In: Peters, A., and Morrison, J.H. (Eds.), Neurodegenerative and age-related changes in structure and function of cerebral cortex. Kluwer Academic/Plenum Publishers. New York, Boston, Dordrecht, London, Moscow, pp. 475-512.

Braak, H., Del Tredici, K., Rüb, U., de Vos, R.A.I., Jansen Steur, E.N.H., Braak, E., 2003. Staging of brain pathology related to sporadic Parkinson's disease. Neurobiol. Aging 24, 197-211.

Choi, J., Levey, A.I., Weintraub, S.T., Rees, H.D., Gearing, M., Chin, L.S., Li, L., 2004. Oxidative modifications and down-regulation of ubiquitin carboxyl-terminal hydrolase L1 associated with idiopathic Parkinson's and Alzheimer's disease. J. Biol. Chem. 279, 13256-13264.

Ciechanover, A., 1998. The ubiquitin-proteasome pathway: on protein death and cell life. EMBO J. 17, 7151-7160.

Dalfó, E., Albasanz, J.L., Martín, M., Ferrer, I., 2004. Abnormal metabotropic glutamate receptor expression and signaling in the cerebral cortex in diffuse Lewy body disease is associated with irregular $\alpha$-synuclein/phospholipase c (plc $\beta 1)$ interactions. Brain Pathol. 14, 388-398.

Forno, L.S., 1996. Neuropathology of Parkinson's disease. J. Neuropathol. Exp. Neurol. 55, 259-272.

Glickman, M.H., Ciechanover, A., 2002. The ubiquitin-proteasome proteolytic pathway: destruction for the sake of construction. Physiol. Rev. 82, 373-428.

Groetrup, M., Soza, A., Eggers, M., Kuehn, L., Dick, T.P., Schild, H., et al., 1996. A role for proteasome regulator PA28 $\alpha$ in antigen presentation. Nature 381, 166-168.

Herschko, A., Ciechanover, A., 1998. The ubiquitin system. Annu. Rev. Biochem. 67, 425-479.

Ince, P.G., McKeith, I., 2003. Dementia with Lewy bodies. In: Dickson, D. (Ed.), Neurodegeneration: The Molecular Pathology of Dementia and Movement Disorders. ISN Neuropathol Press, Basel, pp. 188-199.

Ince, P.G., Perry, E.K., Morris, C.M., 1998. Dementia with Lewy bodies. A distinct non-Alzheimer dementia syndrome? Brain Pathol. 8, 299-324.

Jellinger, K.A., Mizuno, Y., 2003. Parkinson's disease. In: Dickson, D. (Ed.), Neurodegeneration: The Molecular Pathology of Dementia and Movement Disorders. ISN Neuropathol Press, Basel, pp. 159-187.

Kosaka, K., 1990. Diffuse Lewy body disease in Japan. J. Neurol. 237, $197-204$

Kosaka, K., 1993. Dementia and neuropathology in Lewy body disease. Adv. Neurol. 60, 456-463.

Kurihara, L.J., Semenova, E., Levorse, J.M., Tilghman, S.M., 2000. Expression and functional analysis of Uch-L3 during mouse development. Mol. Cell. Biol. 7, 2498-2504.
Kurihara, L.J., Kikuchi, T., Wada, K., Tilghman, S.M., 2001. Loss of UchL1 and Uch-L3 leads to neurodegeneration, posterior paralysis and dysphagia. Hum. Mol. Genet. 10, 1963-1970.

Lansbury, P.T., Brice, A., 2002. Genetics of Parkinson's disease and biochemical studies of implicated gene products. Curr. Opin. Genet. Dev. 13, 299-306.

Larsen, C.N., Price, J.S., Wilkinson, K.D., 1996. Substrate binding and catalysis by ubiquitin C-terminal hydrolases: identification of two active site residues. Biochemistry 35, 6735-6744.

Larsen, C.N., Krantz, B.A., Wilkinson, K.D., 1998. Substrate specificity of de-ubiquitinating enzymes: ubiquitin C-terminal hydrolases. Biochemistry $37,3358-3368$.

Leroy, E., Boyer, R., Auburger, G., Leube, B., Ulm, G., Mezey, E., Harta, G., Brownstein, M.J., Jonnalagada, S., Chernova, T., Dehejia, A., Lavedan, C., Gasser, T., Steinbach, P.J., Wilkinson, K.D., Plymeropoulos, M.H., 1998. The ubiquitin pathway in Parkinson's disease. Nature $395,451-452$.

Li, J., Rechsteiner, M., 2001. Molecular dissection of the 11S REG (PA28) proteasome activators. Biochimie 83, 373-383.

Liu, Y., Fallon, L., Lashuel, H.A., Liu, Z., Lansbury, P.T., 2002. The UCHL1 gene encodes two opposing enzymatic activities that affect $\alpha$ synuclein degradation and Parkinson's disease susceptibility. Cell 111, 209-218.

Lowe, J., McDermott, H., Landon, M., Mayer, R.J., Wilkinson, K.D., 1990 Ubiquitin carboxyl-terminal hydrolase (PGP 9.5) is selectively present in ubiquitinated inclusion bodies characteristic of human neurodegenerative diseases. J. Pathol. 161, 153-160.

Maraganore, D.M., Farrer, M.J., Hardy, J.A., Lincoln, S.J., McDonnell, S.K., Rocca, W.A., 1999. Case-control study of the ubiquitin carboxyterminal hydrolase L1 gene in Parkinson's disease. Neurology 53, $1858-1860$.

Maraganore, D.M., Lesnick, T.G., Elbaz, A., Chartier-Harlin, M.C., Gasser, T., Kruger, R., Hattori, N., Mellick, G.D., Quattrone, A., Satoh, J., Toda, T., Wang, J., Ionnidis, J.P., de Andrade, M., Rocca, W.A., 2004 UCHL-1 is a Parkinson's disease susceptibility gene. Ann. Neurol. 55, $512-521$.

McKeith, I.G., Galasko, D., Kosaka, K., Perry, E.K., Dickson, D.W., Hansen, L.A., Salmon, D.P., Lowe, J., Mirra, S.S., Byrne, E.J., Lennox, G., Quinn, N.P., Edwardson, J.A., Ince, P.G., Bergeron, C., Burns, E.J., Miller, B.L., Lovestone, S., Collerton, D., Jansen, E.N., Ballard, C., de Vos, R.A., Wilcock, G.K., Jellinger, K.A., Perry, R.H., 1996. Consensus guidelines for the clinical and pathologic diagnosis of dementia with Lewy bodies (DLB): Report of the consortium on DLB international workshop. Neurology 47, 1113-1124.

McKeith, I.G., Ballard, C.G., Perry, R.H., Ince, P.G., O’Brien, J.T., Neill, D., Lowery, K., Jaros, E., Barber, R., Thompson, P., Swann, A., Fairbairn, A.F., Perry, E.K., 2000. Prospective validation of consensus criteria for the diagnosis of dementia with Lewy bodies. Neurology 54 , $1050-1058$.

McNaught, K.S., Jenner, P., 2001. Proteasomal function is impaired in substantia nigra in Parkinson's disease. Neurosci. Lett. 297, 191-194.

McNaught, K.S., Olanow, C.W., 2003. Proteolytic stress: a unifying concept for the etiopathogenesis of Parkinson's disease. Ann. Neurol. $53, \mathrm{~S} 73-\mathrm{S} 84$.

McNaught, K.S., Olanow, C.W., Halliwell, B., Isacson, O., Jenner, P., 2001. Failure of the ubiquitin-proteasome system in Parkinson's disease. Nat. Rev., Neurosci. 2, 589-594.

McNaught, K.S., Mytilineou, C., Jnobaptiste, R., Yabut, J., Shashidharan, P., Jennert, P., et al., 2002a. Impairment of the ubiquitin-proteasome system causes dopaminergic cell death and inclusion body formation in ventral mesencephalic cultures. J. Neurochem. 81, 301-306.

McNaught, K.S., Belizaire, R., Jenner, P., Olanow, C.W., Isacson, O., 2002b. Selective loss of $20 \mathrm{~S}$ proteasome alpha-subunits in the substantia nigra pars compacta in Parkinson's disease. Neurosci. Lett. 326, 155-158.

McNaught, K.S., Belizaire, R., Isacson, O., Jenner, P., Olanow, C.W., 2003. Altered proteasomal function in sporadic Parkinson's disease. Exp. Neurol. 179, 38-46. 
Miller, R.M., Kiser, G.L., Kaysser-Kranich, T.M., Lockner, R.J., Palaniappan, C., Federoff, H.J., in press. Robust dysregulation of gene expression in substantia nigra and striatum in Parkinson's disease. Neurobiol. Dis.

Miura, H., Oda, K., Endo, C., Yamazaki, K., Shibasaki, H., Kikuchi, T., 1993. Progressive degeneration of motor nerve terminals in GAD mutant mouse with hereditary sensory axonopathy. Neuropathol. Appl. Neurobiol. 19, 41-51.

Mukoyama, M., Yamazaki, K., Kikuchi, T., Tomita, T., 1989. Neuropathology of gracile axonal dystrophy (GAD) mouse. An animal model of central distal axonopathy in primary sensory neurons. Acta Neuropathol. 79, 294-299.

Nishikawa, K., Li, H., Kawamura, R., Osaka, H., Wang, Y.L., Hara, Y., Hirokawa, T., Manago, Y., Amano, T., Noda, M., Aoki, S., Wada, K., 2003. Alterations of structure and hydrolase activity of parkinsonismassociated human ubiquitin carboxyl-terminal hydrolase L1 variants. Biophys. Res. Commun. 304, 176-183.

Oda, K., Yamazaki, K., Miura, H., Shibasaki, H., Kikuchi, T., 1992. Dying back type axonal degeneration of sensory nerve terminals in muscle spindles of the gracile axonal dystrophy (GAD) mutant mouse. Neuropathol. Appl. Neurobiol. 18, 265-281.

Osaka, H., Wang, Y.L., Takada, K., Takizawa, S., Setsuie, R., Li, H., Sato, Y., Nishikawa, K., Sun, Y.J., Sakurai, M., Harada, T., Hara, Y., Kimura, I., Chiba, S., Namikawa, K., Kiyama, H., Noda, M., Aoki,
S., Wada, K., 2003. Ubiquitin carboxy-terminal hydrolase L1 binds to and stabilizes monoubiquitin in neuron. Hum. Mol. Genet. 12, $1945-1958$.

Saigoh, K., Wang, Y.L., Suh, J.G., Yamanishi, T., Sakai, Y., Kiyosawa, H., Harada, T., Ichihara, N., Wakana, S., Kikuchi, T., Wada, K., 1999. Intragenic deletion in the gene encoding ubiquitin carboxy-terminal hydrolase in gad mice. Nat. Genet. 23, 47-51.

Solano, S.M., Miller, D.W., Augood, S.J., Young, A.B., Penney Jr., J.B., 2000. Expression of alpha-synuclein, parkin, and ubiquitin carboxyterminal hydrolase L1 mRNA in human brain: genes associated with familial Parkinson's disease. Ann. Neurol. 47, 201-210.

Spillantini, M.G., Crowther, R.A., Jakes, R., Hasegawa, M., Goedert, M., 1998. $\alpha$-synuclein in filamentous inclusions of Lewy bodies from Parkinson's disease and dementia with Lewy bodies. Proc. Natl. Acad. Sci. U. S. A. 95, 6469-6473.

Tanaka, K., Tsurumi, C., 1997. The 26S proteasome: Subunits and functions. Mol. Biol. Rep. 24, 3-11.

Tofaris, G.K., Razzaq, A., Ghetti, B., Lilley, K.S., Spillantini, M.G., 2003. Ubiquitination of $\alpha$-synuclein in Lewy bodies is a pathological event not associated with impairment of proteasome function. J. Biol. Chem. 278, 44405-444011.

Wilkinson, K.D., Lee, K.M., Deshpande, S., Duerksen-Hughes, P., Boss, J.M., Pohl, J., 1989. The neuron-specific protein PGP 9.5 is a ubiquitin carboxyl-terminal hydrolase. Science 246, 670-673. 